Artículo

\title{
Especies de Phytophthora asociadas a agua de irrigación en el Valle de Culiacán
}

\author{
Josué Cárdenas Rodríguez ${ }^{1 \S}$ \\ Moisés Gilberto Yáñez Juárez ${ }^{1}$ \\ Carlos Alfonso López Orona ${ }^{1}$ \\ Felipe Ayala Tafoya ${ }^{1}$ \\ Guadalupe Alfonso López Urquidez ${ }^{1}$ \\ Sergio de Jesús Romero Gómez ${ }^{2}$
}

${ }^{1}$ Facultad de Agronomía-Universidad Autónoma de Sinaloa. Carretera Culiacán-Eldorado km 17.5, Culiacán Rosales, Sinaloa, México. AP. 25. CP. 80000. (moisesyj@uas.edu.mx; clopezorona@uas.edu.mx; tafoya@uas.edu.mx; alfonsolopezurquidez@uas.edu.mx). ${ }^{2}$ Facultad de Química-Universidad Autónoma de Querétaro. Centro Universitario Hidalgo s/n, Cerro de las Campanas, Querétaro. CP. 76010. (ser69rom@gmail.com).

${ }^{\S}$ Autor para correspondencia: j.cardenasrodriguez@hotmail.com.

\section{Resumen}

En México existen escasos estudios que describen a los cuerpos acuáticos empleados para la agricultura y el rol que tiene el agua de riego como fuente de inóculo, persistencia y dispersión de parásitos fitopatógenos, tal es el caso de los oomycetes que habitan ambientes acuáticos con capacidad de infectar un amplio rango de hospedantes cultivados. Debido a la falta de información sobre qué géneros y especies de oomycetes están presentes en el agua, su identificación es de suma importancia para gestionar alternativas de manejo y control de estos para la producción agrícola en la región. Con el objetivo de determinar qué oomycetes se aíslan en aguas superficiales empleadas para la irrigación en el Valle de Culiacán, Sinaloa, en el periodo comprendido de septiembre de 2018 a enero de 2019, en diferentes redes hídricas agrícolas (presas, estanques, ríos y canales), se colocaron trampas flotantes elaboradas con bolsas de polipropileno y dos frutos de pera que sirvieron como cebo. Se obtuvieron aislados de oomycetes, los cuales se identificaron en base a sus características morfológicas y secuencias de ADN (con los iniciadores ITS 4/6, COX y NADH), también se realizaron pruebas de patogenicidad en plantas y frutos de las familias de solanáceas y cucurbitáceas. Se aislaron e identificaron los organismos: Phytophthora parsiana, $P$. virginiana, $P$. lagoariana, P. capsici y P. hydropathica. Todas las especies de Phytophthora resultaron patogénicas, tuvieron capacidad de infectar plantas y frutos, causando síntomas de marchitez y pudrición en las hortalizas inoculadas.

Palabras clave: ácidos nucleicos, hortalizas, oomycetes, pseudohongo.

Recibido: diciembre de 2020

Aceptado: marzo de 2021 


\section{Introducción}

Los organismos del género Phytophthora, pertenecen al reino Cromista o Stramenopila, son habitantes de ambientes acuáticos y terrestres, con alta capacidad de reproducción, diseminación y supervivencia, particularidades que facilita su establecimiento en campos de explotación agrícola o forestal (Erwin y Ribeiro, 1996; Chen et al., 2017, Hon, 2018; Judelson et al., 2019). En ese género, se incluyen especies con amplio rango de hospedantes como $P$. cinnamomi que es capaz de parasitar alrededor de 5000 especies de plantas (Hardham et al., 2018) y P. capsici, conocida por originar pérdidas económicas en plantaciones de solanáceae y cucurbitáceae cultivadas alrededor del mundo (Vega et al., 2017).

Alrededor de 30 especies de Phytophthora fueron colectadas en cuerpos de agua como estanques, ríos, canales, reservorios y cultivos hidropónicos (Aram y Rizo, 2018) además, el género Phytophthora al igual que otros oomycetes fitopatógenos requiere estrictamente de agua para su reproducción la cual inicia con la formación de esporangióforos y esporangios, dentro de los cuales se forman las zoosporas para su posterior liberación y diseminación; dichas zoosporas, son capaces de infectar plantas susceptibles e iniciar el ciclo de una enfermedad (Kang et al., 2017).

Las zoosporas son el propágulo infectivo diseminado por agua libre, por ello, es posible recuperarlas con regularidad de aguas superficiales (Hon, 2018). Algunos ejemplos de especies aisladas de agua con frecuencia son: $P$. cactorum, $P$. parasitica, $P$. citrícola, $P$. gonapodyides, $P$. cambivora, $P$. hydropathica y P. drechsleri, entre otras (Loyd, 2014; Redekar y Park, 2018; Ristvey et al., 2019). En México, existen alrededor de 17 especies pertenecientes al género Phytophthora reportadas como parásitos de plantas de importancia agrícola, las más comunes son: $P$. capsici, $P$. infestans y $P$. cinnamomi; sin embargo, es escasa la información sobre la atribución del agua superficial como fuente de inóculo y dispersión de organismos del género Phytophthora.

Así, Álvarez et al. (2016) lograron aislar e identificar las especies $P$. hydropathica y P. drechsleri de distintos canales de agua de uso agrícola en Culiacán, Sinaloa, México. Por otro lado, comúnmente la identificación de géneros y especies de oomycetes se basaba en sus características morfológicas y culturales; sin embargo, fueron frecuentes identificaciones erróneas, debido a que algunas especies comparten dichas características; actualmente, esas prácticas son complementadas mediante técnicas biotecnológicas basadas en la extracción y secuenciación de ácidos nucleicos, lo cual permite la identificación de organismos de forma eficaz y concreta (Trzewik et al., 2016). Por lo anterior, el objetivo del presente estudio fue determinar la incidencia de especies del género Phytophthora en aguas superficiales de uso agrícola en Culiacán, Sinaloa y determinar su potencial patogénico en plantas cultivadas en México.

\section{Materiales y métodos}

\section{Obtención, purificación y conservación de aislamientos Phytophthora spp.}

Dispuesto mapa de ubicación de presas, diques, estanques, ríos y canales de almacenamiento y distribución del agua empleada en actividades agropecuarias, de la zona de influencia del distrito de riego número 010 del Valle de Culiacán, Sinaloa, otorgado por la Comisión Nacional del Agua (CONAGUA) (Figura 1), fueron seleccionados al azar 37 sitios de muestreo en 28 localidades (Cuadro 1). 


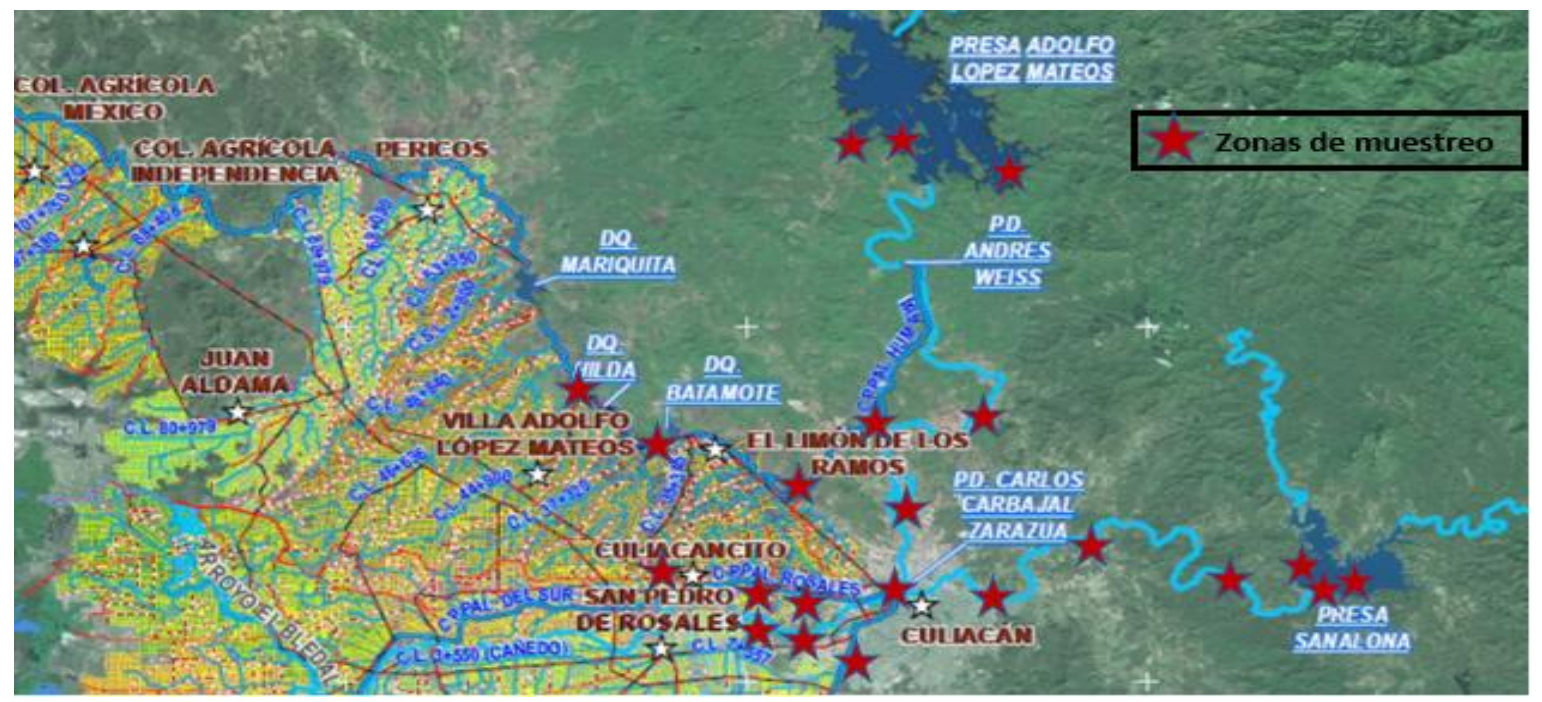

Figura 1. Principales sitios de muestreo en el municipio de Culiacán, Sinaloa. Imagen proporcionada por la CONAGUA.

Cuadro 1. Ubicación geográfica de los sitios de muestro para la obtención de aislamientos de Phytophthora spp., Culiacán, Sinaloa, 2018-2019.

\begin{tabular}{|c|c|c|}
\hline Localidad & Coordenadas del sitio de muestreo & Aislamiento \\
\hline Presa Adolfo López & $25^{\circ} 10^{\prime} 08^{\prime \prime} \mathrm{N} 107^{\circ} 26^{\prime} 10^{\prime \prime} \mathrm{W} 25^{\circ} 09^{\prime} 10^{\prime \prime}$ & PV1, PV2, PV3, PV4, PV5, PV6, \\
\hline Mateos (El Varejonal) & $\begin{array}{c}\mathrm{N} 107^{\circ} 26^{\prime} 11^{\prime} \mathrm{W} 25^{\circ} 09^{\prime} 56^{\prime \prime} \mathrm{N} \\
107^{\circ} 26^{\prime} 30^{\prime \prime} \mathrm{W}\end{array}$ & $\begin{array}{c}\text { PV7, PV8, PV9, PV10, PV11, } \\
\text { PV12 }\end{array}$ \\
\hline La Presita & $24^{\circ} 55^{\prime} 49^{\prime \prime} \mathrm{N} 107^{\circ} 25^{\prime} 39^{\prime \prime} \mathrm{W}$ & PR13, PR14, PR15, PR16 \\
\hline Empaque Castro & 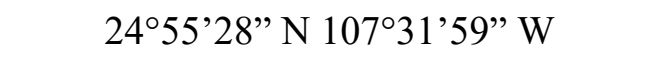 & EC17, EC18, EC19, EC20 \\
\hline El Tamarindo & $\begin{array}{l}24^{\circ} 55^{\prime} 07^{\prime \prime} \mathrm{N} 107^{\circ} 333^{\prime} 32^{\prime \prime} \mathrm{W} \\
24^{\circ} 55^{\prime} 11^{\prime \prime} \mathrm{N} 107^{\circ} 32^{\prime} 57^{\prime \prime} \mathrm{W}\end{array}$ & TR21, TR22, TR23, TR24 \\
\hline Empaque Valle del sol & $24^{\circ} 53^{\prime} 20^{\prime \prime} \mathrm{N} 107^{\circ} 29^{\prime} 17^{\prime \prime} \mathrm{W}$ & EVS25, EVS26, EVS27, EVS28 \\
\hline Presa Sanalona & $\begin{array}{c}24^{\circ} 48^{\prime} 37^{\prime \prime} \mathrm{N} 107^{\circ} 08^{\prime} 11^{\prime \prime} \mathrm{W} 24^{\circ} 48^{\prime} 46^{\prime \prime} \\
\mathrm{N} 107^{\circ} 08^{\prime} 14^{\prime \prime} \mathrm{W} 24^{\circ} 48^{\prime} 49^{\prime \prime} \mathrm{N} \\
107^{\circ} 08^{\prime} 30^{\prime \prime} \mathrm{W}\end{array}$ & $\begin{array}{c}\text { PS33, PS34, PS35, PS36, PS37, } \\
\text { PS38, PS39, PS40, PS41, PS2, } \\
\text { PS43 }\end{array}$ \\
\hline Río Tamazula & $\begin{array}{c}24^{\circ} 49^{\prime} 00^{\prime \prime} \mathrm{N} 107^{\circ} 11^{\prime} 16^{\prime \prime} \mathrm{W} 24^{\circ} 48^{\prime} 53^{\prime \prime} \\
\mathrm{N} 107^{\circ} 21^{\prime} 29^{\prime \prime} \mathrm{W}\end{array}$ & $\begin{array}{l}\text { RT44. RT45, RT46, RT47, } \\
\text { RT48, RT49 }\end{array}$ \\
\hline Río Humaya & 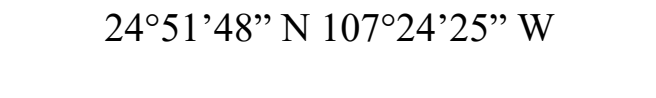 & $\begin{array}{l}\text { RH50, RH51, RH52, RH53, } \\
\text { RH54, RH55 }\end{array}$ \\
\hline Jardín Botánico & $\begin{array}{c}24^{\circ} 49^{\prime} 23^{\prime \prime} \mathrm{N} 107^{\circ} 23^{\prime} 06^{\prime \prime} \mathrm{W} 24^{\circ} 49^{\prime} 24^{\prime \prime} \\
\text { N } 107^{\circ} 23^{\prime} 04^{\prime \prime} \mathrm{W}\end{array}$ & $\begin{array}{l}\text { JB56, JB57, JB58, JB59, JB60, } \\
\text { JB61 }\end{array}$ \\
\hline Imala & $24^{\circ} 51^{\prime} 21^{\prime \prime} \mathrm{N} 107^{\circ} 13^{\prime} 11^{\prime \prime} \mathrm{W}$ & IMA62, IMA63, IMA64, IMA65 \\
\hline Tres Ríos & $\begin{array}{c}24^{\circ} 48^{\prime} 43^{\prime \prime} \mathrm{N} 107^{\circ} 24^{\prime} 24^{\prime \prime} \mathrm{W} 24^{\circ} 48^{\prime} 24^{\prime} \\
\text { N } 107^{\circ} 24^{\prime} 33^{\prime \prime} \mathrm{W}\end{array}$ & $\begin{array}{c}\text { 3R66, 3R67, 3R68, 3R69, 3R70, } \\
\text { 3R71 }\end{array}$ \\
\hline Bellavista & 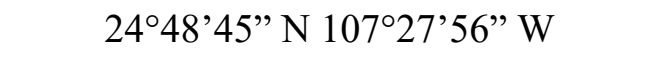 & BELL74 y BELL75 \\
\hline Bachigualato & $24^{\circ} 46^{\prime} 59^{\prime \prime} \mathrm{N} 107^{\circ} 26^{\prime} 48^{\prime \prime} \mathrm{W}$ & ВАCH76 у ВАCH77 \\
\hline Aguaruto & $24^{\circ} 47^{\prime} 49^{\prime \prime} \mathrm{N} 107^{\circ} 30^{\prime} 24^{\prime \prime} \mathrm{W}$ & AGUA78 y AGUA79 \\
\hline Campo Batan & $\begin{array}{c}24^{\circ} 46^{\prime} 10^{\prime \prime} \mathrm{N} 107^{\circ} 30^{\prime} 19^{\prime \prime} \mathrm{W} 24^{\circ} 45^{\prime} 40^{\prime \prime} \\
\mathrm{N} 107^{\circ} 30^{\prime} 45^{\prime \prime} \mathrm{W}\end{array}$ & CB80 y CB81 \\
\hline
\end{tabular}




\begin{tabular}{|c|c|c|}
\hline Localidad & Coordenadas del sitio de muestreo & Aislamiento \\
\hline Campo Moroleón & 2441'14”'N 107³1'09” W & CM82 y CM83 \\
\hline Campo Cardenal & $24^{\circ} 45^{\prime} 10^{\prime \prime} \mathrm{N} 107^{\circ} 28^{\prime} 39^{\prime \prime} \mathrm{W}$ & CC84 y CC85 \\
\hline Dique Primavera & $24^{\circ} 43^{\prime} 48^{\prime \prime} \mathrm{N} 107^{\circ} 24^{\prime} 10^{\prime \prime} \mathrm{W}$ & DP86 y DP87 \\
\hline Estación Hazera & $24^{\circ} 43^{\prime} 32^{\prime \prime} \mathrm{N} 107^{\circ} 27^{\prime} 24^{\prime \prime} \mathrm{W}$ & HAZ88 y HAZ89 \\
\hline Estación Enza Zaden & $24^{\circ} 40^{\prime} 58^{\prime \prime} \mathrm{N} 107^{\circ} 28^{\prime} 47^{\prime \prime} \mathrm{W}$ & EZ90 у EZ91 \\
\hline Estación Monsanto & $24^{\circ} 40^{\prime} 37^{\prime \prime} \mathrm{N} 107^{\circ} 28^{\prime} 50^{\prime \prime} \mathrm{W}$ & MON92 y MON93 \\
\hline Campo Divemex & $24^{\circ} 39^{\prime} 46^{\prime \prime} \mathrm{N} 107^{\circ} 26^{\prime} 58^{\prime \prime} \mathrm{W}$ & DIV94 y DIV95 \\
\hline Estación US Agriseeds & $24^{\circ} 38^{\prime} 11^{\prime \prime} \mathrm{N} 107^{\circ} 26^{\prime} 38^{\prime \prime} \mathrm{W}$ & US96 y US97 \\
\hline Estación Syngenta & $24^{\circ} 37^{\prime} 08^{\prime \prime} \mathrm{N} 107^{\circ} 26^{\prime} 41^{\prime \prime} \mathrm{W}$ & SYN98 y SYN99 \\
\hline Estación Rijk Zwaan & $24^{\circ} 36^{\prime} 12^{\prime \prime} \mathrm{N} 107^{\circ} 26^{\prime} 41^{\prime \prime} \mathrm{W}$ & RZ100 y RZ101 \\
\hline Estación Bayer & $24^{\circ} 36^{\prime} 14^{\prime \prime} \mathrm{N} 107^{\circ} 27^{\prime} 22^{\prime \prime} \mathrm{W}$ & BAY102 у BAY103 \\
\hline Dique Costa Rica & $24^{\circ} 35^{\prime} 44^{\prime \prime} \mathrm{N} 107^{\circ} 18^{\prime} 33^{\prime \prime} \mathrm{W}$ & CR104 y CR105 \\
\hline Facultad de Agronomía & $24^{\circ} 37^{\prime} 28^{\prime \prime} \mathrm{N} 107^{\circ} 26^{\prime} 34^{\prime \prime} \mathrm{W}$ & PP106 y PC107 \\
\hline
\end{tabular}

El periodo de muestreo comprendido de septiembre de 2018 a enero de 2019, por sitio de muestreo se colocó una trampa elaborada con bolsa tipo red de polipropileno, cerrada de la parte anterior con una cuerda del mismo material, conjuntamente, esa cuerda se utilizó para fijar la trampa en algún punto del talud (Figura 2).

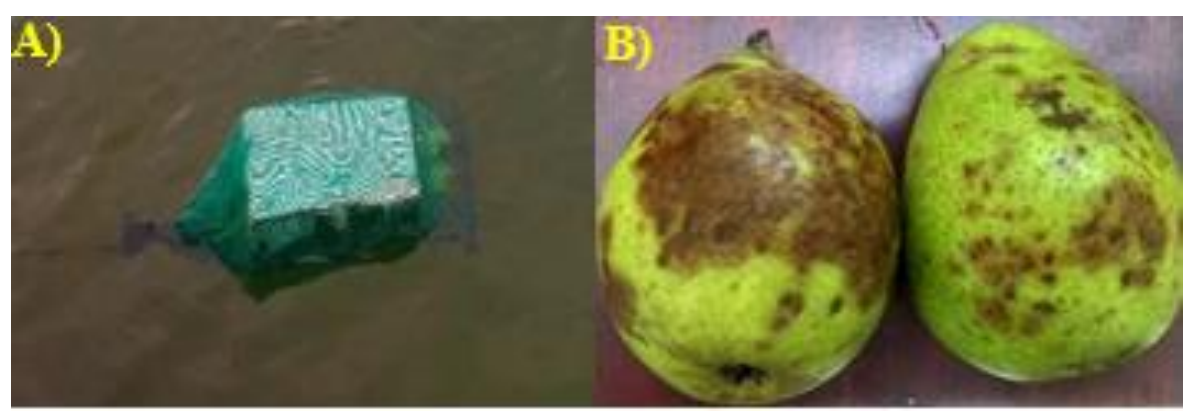

Figura 2. Trampa flotante para muestreo (A) de peras infectadas recuperados de las trampas (B).

Esas trampas, en su interior contenían dos frutos de pera libres de lesiones, lavados con agua simple y desinfestados superficialmente con etanol al $96^{\circ}$ (Soto et al., 2017). Las trampas permanecieron $48 \mathrm{~h}$ en suspensión, posteriormente se colectaron y se transportaron al laboratorio de fitopatología de la Facultad de Agronomía de la Universidad Autónoma de Sinaloa. Los frutos con lesiones evidentes fueron lavados con agua destilada estéril, secados con papel estraza estéril y desinfestados con etanol al $96^{\circ}$.

Los aislamientos se realizaron a partir de cortes de $1 \mathrm{~cm}^{2}$ tomados de las lesiones cafés en los frutos (Figura 2) y cada cinco fragmentos fueron colocados de forma equidistante en cajas de Petri que contenían medio de cultivo selectivo elaborado con harina de maíz-agar (HMA, $17 \mathrm{~g} \mathrm{~L}^{-1}$ ), penicilina $\left(10 \mu \mathrm{g} \mathrm{L}^{-1}\right)$, ampicilina $\left(200 \mu \mathrm{g} \mathrm{L}^{-1}\right)$, rifampicina $\left(10 \mu \mathrm{g} \mathrm{L}^{-1}\right)$, pentacloronitrobenceno (PCNB, $25 \mu \mathrm{g} \mathrm{L}^{-1}$ ) (PARP) (Jeffers, 2006; Soto et al., 2017). 
Las cajas de Petri se dejaron dos días a temperatura ambiente $\left(26 \pm 2{ }^{\circ} \mathrm{C}\right)$. Con la finalidad de purificar y conservar cepas individuales a partir de las colonias desarrolladas del tejido enfermo, se transfirió a medio de cultivo HMA mediante la técnica de punta de hifa, colocadas $48 \mathrm{~h}$ a temperatura ambiente, una vez desarrolladas las colonias, con saca bocado se tomó individualmente de cada aislamiento cinco trozos de $0.5 \mathrm{~cm}$ de diámetro de medio de cultivo con crecimiento micelial para posteriormente colocarlos en tubos microviales $(5 \mathrm{ml})$ que contenían agua destilada estéril y se conservaron a $15^{\circ} \mathrm{C}$ para posteriores estudios (Jeffers, 2006; Abad et al., 2012; Soto et al., 2017).

\section{Características morfológicas y culturales}

Para realizar la caracterización morfológica de los organismos, de las cepas conservadas en tubos microviales se tomó individualmente fragmentos de micelio que fueron sembrados en medio de cultivo que contenía agua destilada $(800 \mathrm{ml})$, jugo V8 $(200 \mathrm{ml}), \mathrm{CaCO}_{3}(2 \mathrm{~g})$ y agar (15 g) (V8A), con la finalidad de inducir el crecimiento y reproducción del patógeno, las cajas de Petri permanecieron $72 \mathrm{~h}$ a temperatura ambiente, posteriormente, con saca bocado se tomó de cada aislamiento cinco fragmentos de $0.5 \mathrm{~cm}$ de diámetro que fueron colocados en cajas de Petri de 90 mm de diámetro que contenían agua destilada y extracto acuoso de suelo que sirvió para la inducción a la formación de esporangios.

Las cajas se incubaron temperatura ambiente por $72 \mathrm{~h}$ (Martin et al., 2004; Jeffers, 2006; Soto et $a l ., 2017)$. Con el propósito de inducir otras estructuras morfológicas como: clamidosporas, hinchamientos hifales, anteridios, oogonios y oosporas, de las cepas conservadas en tubos microviales se tomaron individualmente fragmentos de micelio que fueron sembrados en cajas de Petri que contenían medio de cultivo V8Aclarificado (jugo V8 sometido a 4000 RPM durante 20 min, V8AC) y puestas durante 21 días bajo condiciones de temperatura ambiente y oscuridad.

Se determinó el tipo de compatibilidad sexual reproductiva, para lo cual cada aislamiento se confrontó con linajes de referencia de $P$. capsici y $P$. drechsleri con afinidad A1/A2 (organismos proporcionados del cepario de hongos fitopatógenos de la Universidad Autónoma de Occidente Campus Los Mochis, Sinaloa). Todas las cepas conservadas fueron confrontadas en medio de cultivo V8AC, para lo cual se sembró un cilindro de $0.5 \mathrm{~cm}$ de diámetro de medio de cultivo con crecimiento micelial en un extremo de la caja y en al extremo opuesto se colocó individualmente un cilindro de la cepa A1 o A2, para después mantenerlas a temperatura ambiente y oscuridad durante veintiún días (Jeffers, 2006; Abad et al., 2012; Soto et al., 2017). La caracterización morfológica de aislamientos se realizó mediante la observación de las estructuras desarrolladas con microscopio óptico (Leica DM100 con medidor ocular) y comparación con una clave pictórica de especies del género Phytophthora (Abad et al., 2012).

\section{Identificación molecular}

\section{Extracción del ADN}

Para la extracción de ADN se utilizó el método Bromuro de Cetiltrimetilamonio (CTAB), que consiste en una serie de pasos presentados a continuación: Se colectaron 100-200 mg de micelio desarrollado sobre medio papa dextrosa agar (39 $\mathrm{g} \mathrm{L}^{-1}$, PDA). El micelio se colocó sobre morteros individuales, se añadió nitrógeno líquido a cada muestra y se trituraron con un pistilo hasta obtener un polvo fino. 
El polvo se transfirió individualmente a tubos eppendorf de $2 \mathrm{ml}$ sostenidos en congelación y se añadió $1 \mathrm{ml}$ de buffer de extracción (CTAB 2\%, TRISH-HCl 100 mM PH 8, EDTA 20 mM PH 8, $\mathrm{NaCl} 1.4 \mathrm{M}, \beta$-mercaptoetanol 2\%). Se colocaron los tubos en vortex durante un minuto. Los tubos se insertaron en una centrifuga a 12000 RPM por 15 minutos. El sobrenadante se recuperó y se transfirió individualmente a nuevos tubos eppendorf de $2 \mathrm{ml}$ que contenían $1 \mathrm{ml}$ de solución alcohol cloroformo-isoamílico (49:1), se mezcló el contenido de los tubos con la fase recuperada.

Se colocaron las muestras en vortex por $10 \mathrm{~min}$. Se realizó una segunda recuperación de fase acuosa y una segunda transferencia a nuevos tubos eppendorf. Se añadió acetato de sodio $3 \mathrm{M}$ con $1 \mathrm{ml}$ de alcohol isopropílico con valor $1 / 10$ del volumen recuperado y se almacenaron los tubos a $-20{ }^{\circ} \mathrm{C}$ por 20 min (los tubos pueden ser almacenados hasta por $24 \mathrm{~h}$ para maximizar la obtención de ADN). Se centrifugaron los tubos a 12000 RPM por 15 min, posteriormente se decantaron sin desperdiciar el contenido de ADN precipitado. Se añadió $1 \mathrm{ml}$ de etanol individualmente y se centrifugaron las muestras por $3 \mathrm{~min}$. Se extrajo el sobrenadante sin tocar la fase sólida, se colocaron los tubos con la fase solida a temperatura ambiente para la evaporación de líquidos.

El ADN fue disuelto en $50 \mu \mathrm{l}$ de buffer TE. Las características del ADN se calcularon con Nanodrop a 260 nM, la calidad se estimó con la proporción 280/260, la integridad se visualizó en una cámara de electroforesis en gel de agarosa al $0.8 \%$ con una solución amortiguadora de 1X TAE.

\section{Amplificación, purificación y secuenciación del ADN}

La mezcla de reacción consistió en $1 \mu \mathrm{l}$ de $\operatorname{ADN}\left(50 \mathrm{ng} \mu \mathrm{l}^{-1}\right), 0.5 \mu \mathrm{l}$ de dntp's, 0.25 de Taq ADN polimerasa, $2.5 \mu \mathrm{l}$ de buffer, $0.625 \mu \mathrm{l}$ de cada primer, $20.175 \mu \mathrm{l}$ de agua en un volumen total de reacción de $25 \mu \mathrm{l}$. La amplificación del ADN se realizó en un termociclador (Bio rad T100). La secuencia del termociclador fue la siguiente: una inicial desnaturalización a $94{ }^{\circ} \mathrm{C}$ por 2 min; 35 ciclos de desnaturalización a $94{ }^{\circ} \mathrm{C}$ por $30 \mathrm{~s}$ (60 s para COX y NADH), alineamiento por $30 \mathrm{~s} \mathrm{y}$ extensión a $72{ }^{\circ} \mathrm{C}$ por $60 \mathrm{~s}$, la extensión final a $72{ }^{\circ} \mathrm{C}$ por $10 \mathrm{~min}$. La temperatura de alineamiento fue de $52{ }^{\circ} \mathrm{C}$ para COX, $53{ }^{\circ} \mathrm{C}$ para NADH y $62{ }^{\circ} \mathrm{C}$ para ITS (Cuadro 2), cuya amplificación exitosa fue confirmada por el gel de electroforesis.

Cuadro 2. Iniciadores utilizados para la amplificación de ADN de Phytophthora spp. (Kroon et al., 2004).

\begin{tabular}{ccc}
\hline Primer & Secuencia de primer & $\begin{array}{c}\text { Tamaño } \\
(\mathrm{pb})\end{array}$ \\
\hline ITS4C0569ITS6C0570 & TCCTCCGCTTATTGATATGCGAAGGTGAAGTCGTAACAAGG & 930 \\
COXF4NCOXR4N & GTATTTCTTCTTTATTAGGTGCGTGAAGTAATGTTACATATAC & 972 \\
NADHF1NADHR1 & CTGTGGCTTATTTTACTTTAGCAGCAGTATACAAAAAGCAAC & 897 \\
\hline
\end{tabular}

Los productos de PCR se purificaron mediante el kit wizard SV Gel and PCR CleanUp System (Promega, USA). Ambas cadenas del amplicón se secuenciaron en las instalaciones de Macrogen, Korea. Los resultados de los aislamientos se analizaron por Blast comparando secuencias de aislados depositadas en la base de datos especializada de Phytophthora (www.phytophthoradb.org, www.phytophthora-ID.org) y en NCBI (www.NCBI.com) para determinar el porcentaje de similitud. 


\section{Pruebas de patogenicidad}

\section{Obtención de plántulas}

Con la finalidad de comprobar la patogenicidad de cada uno de los aislados, se produjeron plántulas de tomate saladette ( $c v$ SV-3543), chile bell ( $c v$ Caravaggio) y pepino tipo slicer ( $c v$ Luxell). Las semillas de cada especie se sembraron individualmente en charolas de poliestireno con 256 cavidades rellenas con sustrato peat moss humedecido (Berger), una vez sembradas, las charolas permanecieron en condiciones de invernadero.

Siete días después de la emergencia de plántulas, fueron trasplantadas en macetas de plástico que contenían $2 \mathrm{~kg}$ de sustrato peat moss y se fertiregaron cada tres días con una mezcla de agua y Maxigrow (composición porcentual $\mathrm{g} \mathrm{L}^{-1}$ : extractos orgánicos 112, auxinas 0.09 , giberelinas 0.1 , citoquininas 1.5 , nitrógeno 6.6 , fósforo 13.3 , potasio 13.3 , calcio 2 , magnesio 4 , hierro 17.2 , zinc 26.5, manganeso 13.3 y cobre 13.3).

\section{Pruebas de patogenicidad en plantas}

Para la inoculación de las plántulas cada aislamiento se transfirió a cajas de Petri con medio PARP y se incubaron por 10 días, posteriormente, de cada aislamiento se tomaron cortes $1 \mathrm{~cm}^{2}$ de medio de cultivo con crecimiento micelial y se colocó individualmente sobre los tallos de las plantas al ras del sustrato (25 días después del trasplante), inmediatamente se cubrió el inóculo con sustrato; cinco días después de la inoculación, los riegos fueron más abundantes para favorecer la infección. Se determinó la patogenicidad de los aislamientos mediante observación diaria en un periodo de 20 días.

\section{Pruebas de patogenicidad en frutos}

Frutos de tomate, chile y pepino con madurez fisiológica (libres de lesiones superficiales), lavados con agua destilada estéril y desinfestados con etanol al 70\%, se inocularon y se colocaron dentro de cámaras húmedas en recipientes plásticos, se inocularon con cortes de $1 \mathrm{~cm}^{2}$ de medio de cultivo Parp con 10 días de crecimiento y se les añadió agua destilada estéril para a crear un ambiente favorable al organismo.

Tres días después de la inoculación, la severidad de la enfermedad se determinó en base a la medición de la superficie dañada en $\mathrm{cm}^{2}$ por el patógeno. En las pruebas de patogenicidad de plantas y frutos se utilizaron cuatro repeticiones y su respectivo control (sin inoculación del patógeno). Se realizaron reaislamientos a partir de tejido enfermo tomado de plantas inoculados para comprobar los postulados de Koch.

\section{Resultados y discusión}

Se obtuvieron 17 aislamientos pertenecientes al género Phytophthora, los que se clasificaron en dos grupos tomando en cuenta su similitud morfológica (Cuadro 3): el primer grupo lo conformaron 14 aislamientos que desarrollaron esporangióforos simples, esporangios ovoides no papilados con dimensiones promedio largo y ancho 47.5-60 x 26.25-32.5 $\mu \mathrm{m}$ (TR21, PS36, 3R68, CR104 y 
AGUA79), 47.5-57.5 x 26.25-32.5 $\mu \mathrm{m}$ (PV1, PV11, JB61, CC84 у CC85), 45-60 x 22.5-32.5 $\mu \mathrm{m}$ (RT45 y RT47) y 45-57.5 x 25-32.5 $\mu \mathrm{m}$ (JB61 y 3R70), con proliferación anidada y extendida, esporangióforos simples e hinchamientos irregulares presentes (Figura 3). No se logró identificar el tipo de compatibilidad de esos aislamientos con cepas de afinidad A1 y A2 de P. drechsleri y $P$. capsici.

Cuadro 3. Características fenotípicas de los aislamientos de Phytophthora spp.

\begin{tabular}{|c|c|c|c|c|c|c|c|}
\hline Grup & Aislamiento & $\begin{array}{l}\text { Forma de } \\
\text { esporangios }\end{array}$ & $\begin{array}{c}\text { Proliferación } \\
\text { de } \\
\text { esporangios }\end{array}$ & $\begin{array}{l}\text { Hinchamientos } \\
\text { miceliales }\end{array}$ & $\begin{array}{l}\text { Dimensiones } \\
\text { (largo y } \\
\text { ancho) del } \\
\text { esporangio } \\
(\mu \mathrm{m})\end{array}$ & Compatibilidad & Oosporas \\
\hline \multirow[t]{4}{*}{1} & $\begin{array}{c}\text { TR21, } \\
\text { PS36, } \\
\text { 3R68, } \\
\text { CR104 y } \\
\text { AGUA79 }\end{array}$ & $\begin{array}{c}\text { Ovoides no } \\
\text { papilados }\end{array}$ & $\begin{array}{l}\text { Anidada y } \\
\text { extendida }\end{array}$ & Presentes & $\begin{array}{c}47.5-60 x \\
26.25-32.5\end{array}$ & Desconocida & - \\
\hline & $\begin{array}{c}\text { PV1, PV11, } \\
\text { JB61, CC84 } \\
\text { y CC85 }\end{array}$ & $\begin{array}{c}\text { Ovoides no } \\
\text { papilados }\end{array}$ & $\begin{array}{l}\text { Anidada y } \\
\text { extendida }\end{array}$ & Presentes & $\begin{array}{l}47.5-57.5 x \\
26.25-32.5\end{array}$ & Desconocida & - \\
\hline & $\begin{array}{c}\text { RT45 y } \\
\text { RT47 }\end{array}$ & $\begin{array}{c}\text { Ovoides no } \\
\text { papilados }\end{array}$ & $\begin{array}{l}\text { Anidada y } \\
\text { extendida }\end{array}$ & Presentes & $\begin{array}{c}45-60 x \\
22.5-32.5\end{array}$ & Desconocida & - \\
\hline & $\begin{array}{c}\text { JB61 y } \\
3 R 70\end{array}$ & $\begin{array}{c}\text { Ovoides no } \\
\text { papilados }\end{array}$ & $\begin{array}{l}\text { Anidada y } \\
\text { extendida }\end{array}$ & Presentes & $\begin{array}{c}45-57.5 x \\
25-32.5\end{array}$ & Desconocida & - \\
\hline 2 & $\begin{array}{l}\text { PC107, } \\
\text { MJB72 y } \\
\text { MPV31 }\end{array}$ & $\begin{array}{l}\text { Ovoides } \\
\text { papilados }\end{array}$ & Simple & Ausentes & $\begin{array}{c}40-68 x \\
17-30\end{array}$ & A1 & $\begin{array}{l}\text { Pleróticas } \\
\text { sin } \\
\text { ornamentas } \\
(22-31 \mu \mathrm{m})\end{array}$ \\
\hline
\end{tabular}

El segundo grupo compuesto por tres aislamientos (PC107, MJB72 y MPV31), los que desarrollaron esporangios ovoides papilados, dimensiones promedio largo y ancho de 40.0-68.0 $\mathrm{x}$ 17-30 $\mu \mathrm{m}$, esporangióforos simples, esporangios simples (sin proliferación) y papilados; sin presencia de hinchamientos en las hifas. Reproducción sexual con afinidad A1 de P. capsici, con formación de oosporas pleróticas, sin ornamentas y diámetro promedio de 22-31 $\mu \mathrm{m}$ (Figura 3).

La comparación de esas características con las descritas en las claves taxonómicas de Erwin y Ribeiro (1996) y de Abad et al. (2012), coinciden con las especies Phytophthora parsiana, $P$. virginiana, $P$. lagoariana, $P$. hydropathica y $P$. capsici. Las reacciones de PCR con los iniciadores ITS (4-6) amplificaron un producto aproximado a $941 \mathrm{pb}$, con los iniciadores COX $972 \mathrm{pb}$ y con los iniciadores NADH $897 \mathrm{pb}$. 


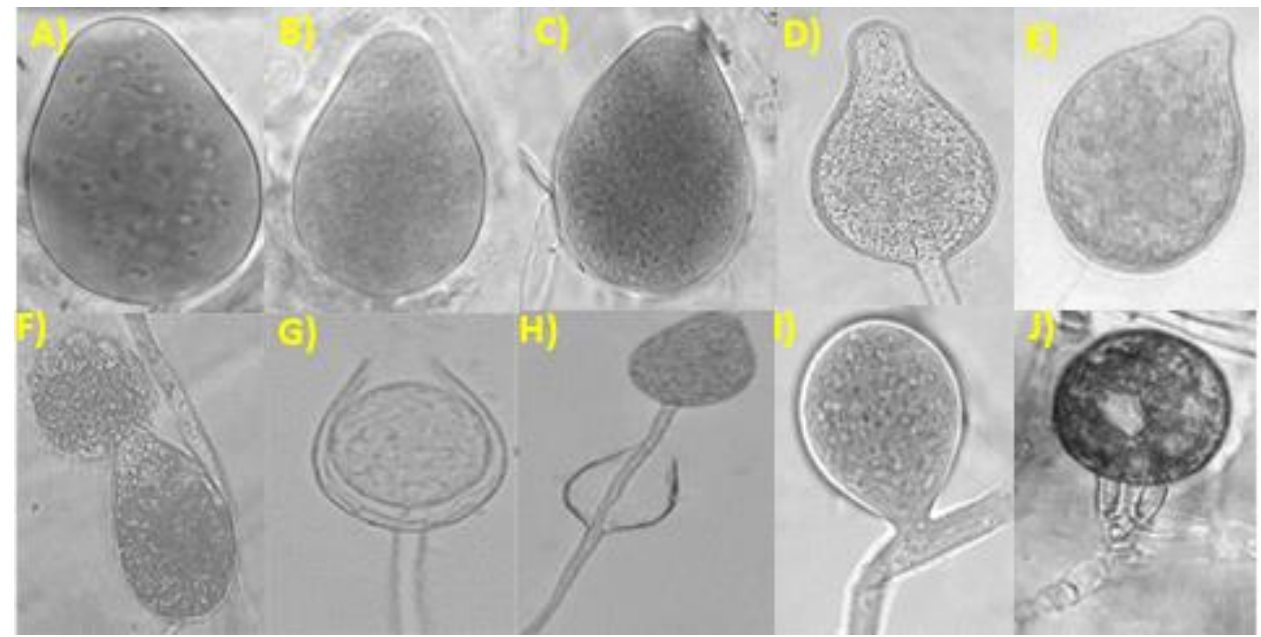

Figura 3. Estructuras sexuales y asexuales de los oomycetes. A-D) esporangios ovoides de Phytophthora spp.; E) esporangio papilado de P. capsici (aislamiento PC107); F) liberación de zoosporas (aislamiento TR21); G) proliferación anidada (aislamiento PV11); H) proliferación extendida (aislamiento JB61); I) hinchamiento del micelio intercalar (aislamiento RT45) y J) oospora de $P$. capsici (aislamiento MPV31).

Las secuencias consenso mostraron resultados con porcentajes de similitud a Phytophthora virginiana: de 99.42 (aislamiento PV1), 99.47 (aislamiento PV11), 99.52 (aislamiento JB61), 99.60 (aislamiento CC84) y 99.78 (aislamiento CC85), para Phytophthora parsiana: de 99 (aislamiento RT45) y 99.22 (aislamiento RT47), para Phytophthora lagoariana: de 98 (aislado JB61) y 98.52 (aislado 3R70), para Phytophthora hydropathica. De 97 (aislamiento TR21), 98 (aislamiento PS36), 98.5 (aislamiento 3R68), 99 (aislamiento CR104) y 99.64 (aislamiento AGUA79) y para Phytophthora capsici de 99.48 (aislamiento PC107), 99.7 (aislamiento MJB72 y 100\% (aislamiento MPV31) (Cuadro 4).

Cuadro 4. Especies de Phytophthora identificadas por aislamiento.

\begin{tabular}{cccc}
\hline Aislamientos & Género & Núm. de acceso (\%) de similitud \\
\hline PV1, PV11, JB61, CC84 y CC85 & Phytophthora virginiana & MT232849 & $99.42-99.78$ \\
RT45 y RT47 & Phytophthora parsiana & MT232850 & $99-99.22$ \\
JB61 y 3R70 & Phytophthora lagoariana & MT232839 & $98-98.52$ \\
TR21, PS36, 3R68, CR104 y AGUA79 & Phytophthora hydropathica & MT339042 & $97-99.64$ \\
PC107, MJB72 y MPV31 & Phytophthora capsici & MT232875 & $99.48-100$ \\
\hline
\end{tabular}

Las especies identificadas en esta investigación son encontradas de manera regular en agua superficial (Zappia et al., 2014, Yang y Hong, 2015). Los 17 aislamientos obtenidos fueron patogénicos, debido a que después de la inoculación todos originaron síntomas de marchitez en plántulas y necrosis de raíz; en frutos causaron síntomas de pudrición (Figura 4). 


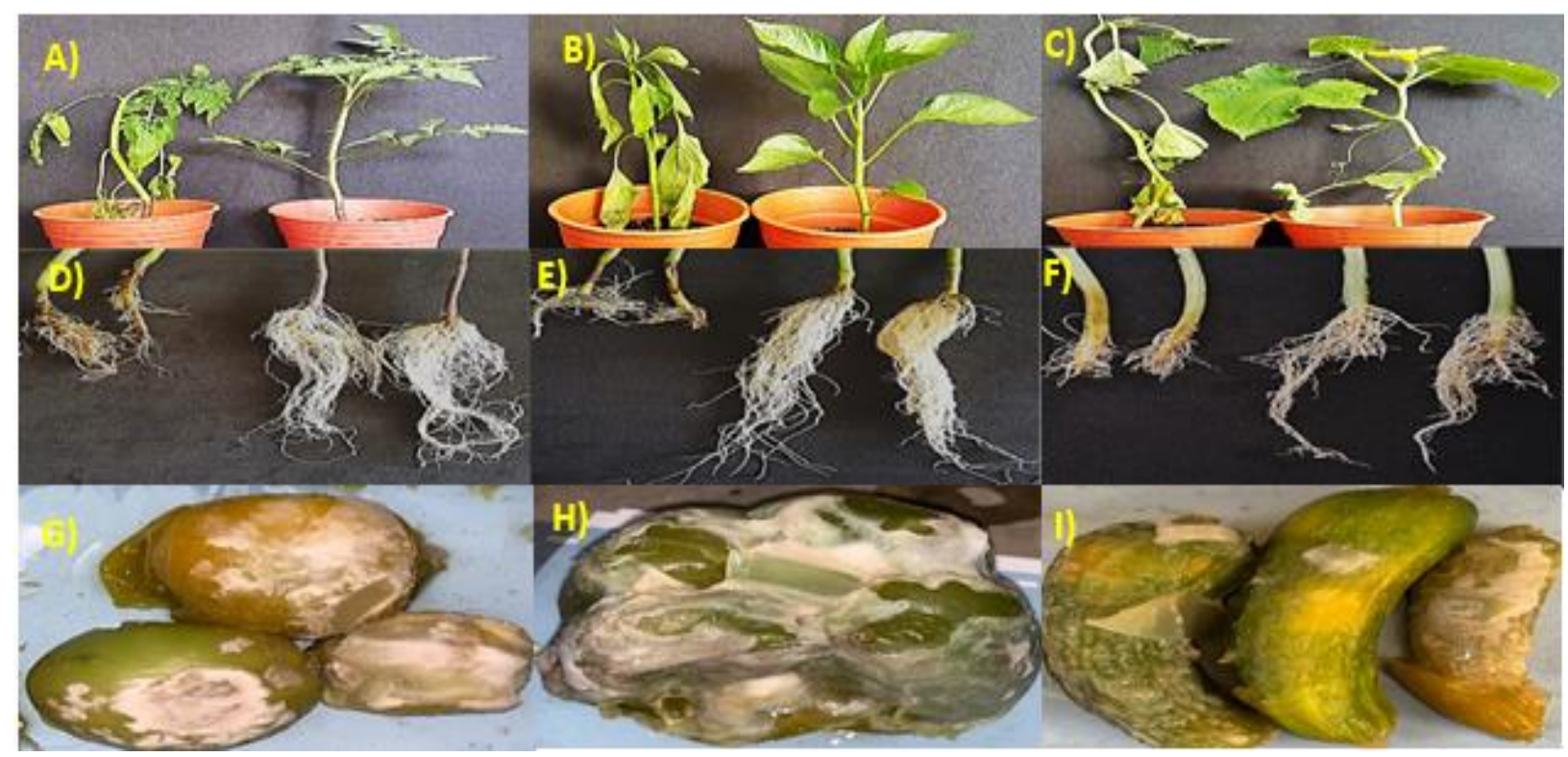

Figura 4. Pruebas de patogenicidad de la especie $P$. hydropathica. A-C) plantas de tomate, chile y pepino, izquierda plantas inoculadas y derecha plantas testigo. D-F) tallos y raíces de plantas de tomate, chile y pepino, izquierda plantas inoculadas y derecha plantas testigo. G-I) frutos inoculados de tomate, chile y pepino.

Los aislamientos de P. capsici originaron marchitez de plantas tres días después de la inoculación, mientras esos mismos síntomas aparecieron 10 días después de la inoculación con el resto de las especies. Estos resultados corroboran el reporte de patogenicidad de Phytophthora parsiana, $P$. virginiana, $P$. lagoariana, $P$. hydropathica y $P$. capsici sobre plantas de tomate, chile y pepino descritos por Cline (2008); Álvarez et al. (2016); Lamour et al. (2012).

Esta investigación comprueba la existencia de especies fitopatógenas no reportadas y que representan un riesgo para la sanidad de cultivos hortícolas en la región. La extracción, amplificación y secuenciación de regiones del ADN de los organismos mediante las técnicas moleculares empleadas en esta investigación (Its, Cox y Nadh), permitió su identificación al determinar niveles de homología entre 97 y $100 \%$ en la base de datos NCBI y con eso, mayor eficiencia que con la tradicional identificación caracterización morfológica.

Este estudio de agua superficial demuestra la presencia en ese hábitat de Phytophthora virginiana, Phytophthora parsiana, Phytophthora lagoariana, Phytophthora hydropathica y Phytophthora capsici; asimismo, la importancia que juega el agua como fuente inóculo y dispersión de esos patógenos. A su vez, se amplía el rango de estudios para futuras investigaciones sobre la supervivencia de este tipo de patógenos, descubrir nuevos hospedantes naturales en la zona, determinar otros posibles medios de diseminación, la búsqueda de nuevos hospedantes de importancia económica, identificar si existe la presencia de otro tipo de patógenos de importancia agrícola en agua, y de este modo considerar el riesgo potencial que este tipo organismos representa para la agricultura de la región. 


\section{Conclusiones}

En aguas superficiales de uso agropecuario del distrito de riego número 10 del Valle de Culiacán, Sinaloa, se colectaron 17 aislamientos que correspondieron a los organismos $P$. virginiana, $P$. parsiana, $P$. lagoariana y Phytophthora capsici, todos con capacidad de infectar plantas y frutos de tomate, chile y pepino.

\section{Agradecimientos}

Al CONACYT por el financiamiento de los estudios de Josué Cárdenas Rodríguez y a la Universidad Autónoma de Sinaloa-Facultad de Agronomía por el apoyo en esta investigación.

\section{Literatura citada}

Abad, Z. G. and Balci, Y. 2012. Identification and detection of Phytophthora: reviewing our progress, identifying our needs. United States of America. Plant Dis. 96(8):1081-1103. Doi: 10.1094/PDIS-12-11-1036-FE.

Álvarez, B; García, R. S; Valdez, J. B.; León, J; Allende, R. and Fernández, S. P. 2016. Phytophthora hydropathica and Phytophthora drechsleri isolated from irrigation channels in the Culiacan Valley. México. Rev. Mex. Fitopatol. 35(1):20-39. Doi: 10.18781/R.MEX.FIT.1606-1.

Aram, K. and Rizzo, D. M. 2018. Distinct trophic specializations affect how to Phytophthora ramorum and clade 6 phytophthora spp. colonize and persit on Umbellularia californica leaves in streams. California. Phytopatlogy. 108(7):858-869. Doi: 10.1094/phyto-0617-0196-R.

Chen, X. and Wang, Y. 2017. Phytophthora sojae. In: biological invasions and its management in China. Simberloff, D. (Ed). Tennessee, USA. 252 p.

Cline, E.; Farr, D. F. and Rossman, A. Y. 2008. A Synopsis of Phytophthora with accurate scientific names, host range, and geographic distribution. Baltimore. Plant Health Progress. 9(1):32-43. Doi: 10.1094/PHP-2008-0318-01-RS.

Erwin, D. C. and Ribeiro, O. K. 1996. Phytophthora diseases worldwide. Minnesota. The American Phytopathological Society. 562 p.

Hardham, A. and Blackman, L. M. 2018. Pathogen profile update Phytophthora cinnamomi. Australia. Plant Pathol. 19(2):260-285. Doi: 10.1111/mpp.12568.

Hon, H. O. 2018. The taxonomy and biology of Phytophthora and Pythium. New York. J. Bacteriol. Mycol. 6(1):40-45. Doi:10.15406/jbmoa.2018.06.00174.

Jeffers, S. N. 2006. Identifying species of Phytophthora. Clemson. Plant Dis. 83(12):1129-1136.

Judelson, H. S. and Ah-Fong, A. M. 2019. Exchanges at the plant-oomycete interface that influence disease. Plant Physiol. 179(4):1198-1211. Doi: 10.1104/pp.18.00979.

Kang, D. S; Min, K. J; Kwakl, A. M; Lee, S. Y. and Kang, H. W. 2017. Defense response and suppression of Phytophthora blight disease of pepper by water extract from spent mushroom substrate of Lentinula edodes. Korea. Plant Pathol. J. 33(3):264-275. Doi: 10.5423/PPJ.OA.02.2017.0030.

Kroon, L. P.; Bakker, F. T; Van, G. B.; Bonants, P. M. and Flier, W. G. 2004. Phylogenetic analysis of Phytophthora species based on mitochondrial and nuclear DNA sequences. Fungal Genet Biol. 41(8):766-782. Doi: 10.1016/j.fgb.2004.03.007. 
Lamour, K. H.; Stam, R.; Jupe, J. and Huitema, E. 2012. The oomycete broad-host-range pathogen Phytophthora capsici. United States. Mol. Plant Pathol. 13(4):329-337. Doi.org/10.1111/j.1364-3703.2011.00754.x.

Loyd, A. L.; Benson, D. M. and Ivors, K. L. 2014. Phytophthora populations in nursery irrigation water in relationship to pathogenicity and infection frequency of Rhododendron and Pieris. North Caroline. Plant Dis. 98(9):1213-1220. Doi: 10.1094/PDIS-11-13-1157-RE.

Martin, F. N.; Tooley, P. W.; and Blomquist, C. 2004. Molecular detection of Phytophthora ramorum, the causal agent of sudden oak death in California, and two additional species commonly recovered from diseased plant material. Phytopathology. 94(6):621-31. Doi: 10.1094/phyto.2004.94.6.621. PMID, 18943487.

Redekar, N. M.; Eberhart, J. L. and Parke, J. L. 2018. Diversity of Phytophthora, Pythium and Phytopythium species in recycled irrigation water in a container nursery. Oregon. Phytobiomes J. 3(1):31-45. Doi: 10.1094/pbiomes-10-18-0043-r.

Ristvey, A. G.; Belayneh, B. E. and Lea, J. 2019. A comparison of irrigation-water containment methods and management strategies between two ornamental production systems to minimize water security threats. United States of America. J. Water. 11(12):2558. Doi: $10.3390 / \mathrm{w} 11122558$.

Soto, A.; Rodríguez, G.; Fernández, Y. L.; Pedraza, M. E.; López, L.; Díaz, M. y Fernández, S. P. 2017. Protocolos de aislamiento y diagnóstico de Phytophthora spp. enfoque aplicado a la investigación. México. Rev. Mex. Cienc. Agríc. 8(8):1867-1880.

Trzewik, A.; Katarzyna, N. and Orlikowska, T. 2016. A simple method for extracting DNA from rhododendron plants infected with Phytophthora spp. for use in PCR. Polonia. J. Plant Protec. Res. 56(1):96-100. Doi: 10.1515/jppr-2016-0014.

Vega, J. C.; Beltrán, H. S.; Sevillano, J. and Moffet, P. 2017. Non-host plant resistance against Phytophthora capsici is mediated in party by members of the I 2 R gene family in Nicotiana spp. Canada. Frontiers in Plance Sci. 8(1):205. Doi:10.3389/fpls.2017.00205.

Yang, X. and Hong, C. X. 2015. Diversity and populations of Phytophthora, Phytopythium and Pythium species recovered from sediments in an agricultural run-off sedimentation reservoir. Virginia. Plant Pathol. 65(1):1118-1125. Doi: 10.1111/ppa.12488.

Zappia, R. E.; Huberli, G. E.; Hardy, J. and Bayliss, K. L. 2014. Fungi and oomycetes in open irrigation systems: knowledge gaps and biosecurity implications. Australia. Plant Pathol. 63(5):961-972. Doi: 10.1111/ppa.12223. 